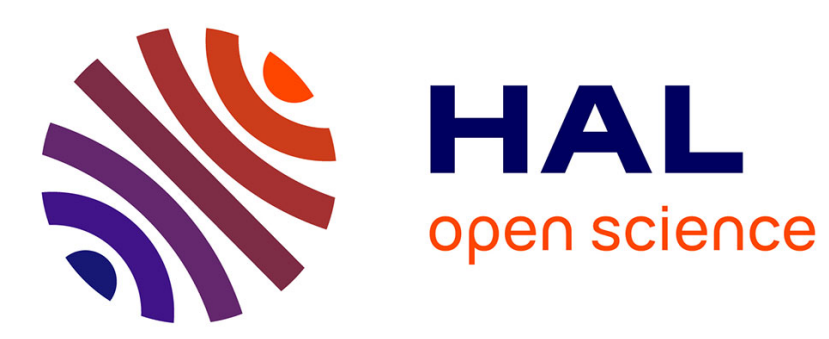

\title{
Multidimensional data analysis for categorical variables
} Gilbert Saporta

\section{To cite this version:}

Gilbert Saporta. Multidimensional data analysis for categorical variables. Peter Nijkamp. Measuring the Unmeasurable, Nato Science Series D: Behavioural and Social Science (22), Springer, pp.317-337, 1985, 978-9024731244. hal-02514123

\section{HAL Id: hal-02514123 https://hal-cnam.archives-ouvertes.fr/hal-02514123}

Submitted on 21 Mar 2020

HAL is a multi-disciplinary open access archive for the deposit and dissemination of scientific research documents, whether they are published or not. The documents may come from teaching and research institutions in France or abroad, or from public or private research centers.
L'archive ouverte pluridisciplinaire HAL, est destinée au dépôt et à la diffusion de documents scientifiques de niveau recherche, publiés ou non, émanant des établissements d'enseignement et de recherche français ou étrangers, des laboratoires publics ou privés. 


\title{
MULTIDIMENSIONAL DATA ANALYSIS
}

FOR CATEGORICAL VARIABLES

\author{
Gi lbert Saporta \\ Conservatoire National \\ des Arts et des Métiers \\ 292, rue Saint-Martin \\ 75141 Paris, France
}

\section{INTRODUCTION}

Before fitting a model to empirical data, an exploratory phase seems essential: a data analytic step where graphics play a major part in understanding the structure of the data.

Until the last decade, not much attention has been paid to the case of categorical variables, even though these occur very frequently in social sciences. Apart from cross-tabulations, unidimensional pie-charts and frequency diagrams, one could not find any other exploratory or descriptive technique for categorical variables in the standard statistical software such as SPSS, BMDP or SAS. (However, Gesitajt al lows correspondence analysis). It is worth noticing that even the recent revival of exploratory techniques tends to ignore multivariate categorical data (e.g., Tukey, 1977, Gnanadesikan, 1977 ) and is focused on metric variables.

However, statistical tools allowing the description of categorical variables similar to principal component analys is for metric data have existed for a long time in the psychometric literature. Rediscovered under the name of correspondence analys is (Benzecri, 1973, Hi 11, 1974, see for an historical survey, Nishisato, 1980) this method is an efficient way of describing multidimensional categorical data and may be associated successfully with other techniques, such as cluster analysis. 
Section 2 is devoted to the bivariate case which is of theoretical and practical importance since many data sets are presented under the form of two-dimensional contingency tables, especially in official statistics. An example concerning French agricultural land use illustrates the use of correspondence and cluster analys is. In Section 3 we show that the analysis of a data set consisting of $n$ individuals described by $p$ categorical variables may be performed by a variant of correspondence analysis which is identical to the principal components of scales proposed by Guttman (1941). An example is given concerning expenditures of consumers in 17 European countries.

\section{DESCRIPTION OF A CONTINGENCY TABLE}

Let $N$ be a two-dimensional contingency table with elements $n_{i j}$, resulting from the cross-classification of two categorical variables $x_{1}$ and $x_{2}$ with $m_{1}$ and $m_{2}$ categories respectively; $D_{1}=\operatorname{diag}\left(n_{j}\right)$ and $D_{2}=\operatorname{diag}\left(n_{j}\right)$ are the diagonal matrices of row and column totals. As an illustration, consider the $22 \times 9$ array giving the distribution of agricultural land use in 1979 for 22 French regions according to 9 categories of land use of holdings. The items represented at the top of the table have the following meaning: CERE: cereals, AGRG: other general agriculture, VINE: vineyards, FRUIT: fruit, MILK: milk production (mainly), MEAT: beef and veal meat production (mainly), SHEEP: sheep, AGSH: general agriculture with sheep.

\section{ILDF ILE DE FRANCE} CHAM CHAMPAGNE=ARDENNE PICA PICARDIE CENT CENTRE BOUR BOURGOGNE NORD NORD-PAS DE CALAIS LORR LORRAINE ALSA ALSACE
FRCO FRANCE-COMTE LOIR PAYS DE LA LOIRE BRET BRETAGNE POIT POITOU-CHARENTES AqUI AQUITAINE MIDI MIDI-PYRENEES LIMO LIMOUSIN RHON RHONE-ALPES
AUVE AUVERGNE

LANG LANGUEDOC-ROUSILLON CORS CORSE HNOR HAUTE NORMANDIE BNOR VASSE NORMANDIE

\begin{tabular}{|c|c|c|c|c|c|c|c|c|}
\hline & GRG & INE & FRUIT & MILK & MEAT & MIX & SHEEP & AGSH \\
\hline 389. & 173.0 & 0.0 & 4.7 & 1.3 & 2.1 & 0.8 & 3.1 & 12.7 \\
\hline $\begin{array}{r}328 \\
188 \\
78\end{array}$ & 135. & $\begin{array}{r}32.1 \\
2.5 \\
0.0 \\
14.1 \\
0.0\end{array}$ & $\begin{array}{r}1.2 \\
3.3 \\
2.8 \\
15.4 \\
2.3 \\
5.5\end{array}$ & $\begin{array}{r}49 \\
47 \\
50 \\
14 . \\
587\end{array}$ & $\begin{array}{r}29.5 \\
12.7 \\
35.9 \\
84.4 \\
94.6 \\
453.8\end{array}$ & $\begin{array}{r}75.0 \\
21.8 \\
87.6 \\
37.8 \\
137.7 \\
129.6\end{array}$ & & $\begin{array}{r}256.5 \\
53.9 \\
192.9\end{array}$ \\
\hline & $\begin{array}{l}50 . \\
31 \\
16\end{array}$ & & $\begin{array}{l}1.1 \\
2.3 \\
1.7 \\
0.8\end{array}$ & $\begin{array}{r}53.3 \\
131 . \\
21.2 \\
279.2\end{array}$ & $\begin{array}{r}31.3 \\
3.6 \\
19.7\end{array}$ & & $\begin{array}{r}47 \\
8 \\
43\end{array}$ & $\begin{array}{r}127.6 \\
134.3 \\
45.2 \\
29.9\end{array}$ \\
\hline $\begin{array}{r}69.9 \\
22.6 \\
178.6\end{array}$ & & & $\begin{array}{r}20.2 \\
3.3 \\
4.9\end{array}$ & & & & & $\begin{array}{r}92.7 \\
54.4 \\
156.2\end{array}$ \\
\hline $\begin{array}{r}166.5 \\
262.5 \\
1.7\end{array}$ & $\begin{array}{r}134.7 \\
227.0 \\
2.9\end{array}$ & $\begin{array}{r}134.3 \\
6.3 \\
0.0\end{array}$ & $\begin{array}{r}27.7 \\
30.0 \\
3.7\end{array}$ & $\begin{array}{r}94 \\
165 \\
43\end{array}$ & & & & $\begin{array}{r}135.9 \\
170.2 \\
8.4\end{array}$ \\
\hline & & & $\begin{array}{r}47.2 \\
2.1\end{array}$ & & & & & $\begin{array}{l}77.5 \\
42.2\end{array}$ \\
\hline $\begin{array}{l}25.9 \\
40.2\end{array}$ & & & & & $\begin{array}{r}51.9 \\
8.9\end{array}$ & & & $\begin{array}{r}9.8 \\
15.9\end{array}$ \\
\hline & 0.6 & 3. & & & 29. & 0.8 & 49.6 & ). \\
\hline
\end{tabular}

Table 1. Agricultural land use for 22 French regions (in 000 ha.)

\subsection{Simultaneous Graphical Display of Rows and Columns}

One of the simplest ways of presenting correspondence analys is is the following method of "reciprocal averaging" or "dual scaling" (Hi11, 1974; Nishisato, 1980). Suppose that the 9 categories of land use are displayed as points with coordinates $b_{j}(j=1, \ldots 9)$ over an axis. It then seems natural to represent the $i$ th region by a point $a_{i}$ which is the weighted mean of the $b_{j}$, where the weights are the conditional frequencies $n_{i j} / n_{j}$.

$$
a_{i}=\sum_{j} \frac{n_{i j}}{n_{i \bullet}} \cdot b j
$$

In vector notation with $\underline{a}=\left(a_{1} \ldots a_{m_{1}^{\prime}}\right)^{\prime}$ and $b \cong\left(b_{1} \ldots b_{m_{1}}\right)^{\prime}$. We have

$$
\underline{a}=D_{1}^{-1} \underline{N}
$$

Of course the $b_{j}$ are arbitrary scores but we may skip this drawback if we want conversely the $b_{j}$ to be centroids of the $a_{j}$ with weights $n_{i j} / n_{j}$

$$
\underline{b}=D_{2}^{-1} N^{\prime} \underline{a}
$$

and by substitution we will get two separate equations.

Unfortunately equations (2) and (3) do not hold simultaneously unless all coordinates are identical which is rather uninteresting: we cannot have at the same time the $b_{j}$ 's as means of the $a_{i}$ 's and vice-versa.

So we need weaker conditions:

$$
\underline{a}=\alpha D_{1}^{-1} N \underline{b} ; \underline{b}=\beta D_{2}^{-1} N^{\prime} \underline{a}
$$

where the constants $\alpha$ and $\beta$ have to be as close as possible to one. Then by substituting we get with $\lambda=(\alpha \beta)^{-1}$

$$
\begin{aligned}
& \lambda \underline{a}=D_{1}^{-1} N^{-1} D_{2}^{\prime} \underline{a} \\
& \lambda \underline{b}=D_{2}^{-1} N^{\prime} D_{1}^{-1} N^{b}
\end{aligned}
$$

The best solution is obtained when choosing the largest eigenvalue less than 1 (ignoring the unit eigenvalue). 
The coordinates of rows and columns are given by the corresponding eigenvectors $\underline{a}$ and $\underline{b}$ of the two matrices $D_{1}^{-1} \mathrm{~N} \mathrm{D}_{2}^{-1} \mathrm{~N}^{\prime}$ and $D_{2}^{-1} \mathrm{~N}^{\prime}$ $D_{1}^{-1} N$ which are the products of the two arrays of conditional frequencies.

It is straightforward to prove that $\alpha=\beta=\lambda^{-1 / 2}$ and that the elimimination of the extraneous solution $\lambda=1$ provides solutions where rows and colums are of zero mean:

$$
\sum_{i} \frac{n_{i j}}{n_{i}} a_{i}=\sum_{j} \frac{n_{i j}}{n \cdot j} b_{j}=0
$$

So far we have obtained a one-dimensional display of the categories of the two variables $x_{1}$ and $x_{2}$.

To obtain two- or higher dimensional plots we have just to take the eigenvectors associated with the second and third largest non-unit eigenvalues of equations $(5)$, as the following subsection will demonstrate.

\subsection{Connection with Principal Components Analys is}

Correspondence analys is is nothing else than two separate but dual principal components analyses performed successively on the rows and then on the columns of $N$. The difference from ordinary P.C.A. consists in using weights for both rows and columns of $N$.

Let us consider the array $D_{1}^{-1} \mathrm{~N}$, that is to say, the matrix of row frequencies associated with $\mathrm{N}$. Region $i$ is described by $\mathrm{m}_{2}$ variables (the row-frequencies) and must of course be weighted by its marginal frequency $n_{j} / n$. If we want to apply P.C.A. to get a lowdimensional configuration of the 22 regions we have moreover to specify some measure of distance between regions. In many respects the so-called chi-square distance (Guttman, 1941):

$$
\left.d_{x^{2}}^{2}\left(i, i^{\prime}\right)=\sum_{j=1}^{m_{2}} \frac{n}{n_{. j}} \frac{\left(n_{i j}^{n_{j}}\right.}{n_{i}}-\frac{n_{i j}}{n_{i}}\right)^{2}
$$

is preferable to the usual one without the $n$ terms since it avoids the implicit discarding of categories with sihall frequencies in computing the distance.
But the importance of the chi-square distance relies on the following property: the two possible P.C.A., for rows and for columns, are in a strict duality when choosing chi-square distance for rows and for columns respectively.

More precisely, in the first analysis the matrix of weighted sums of squares and products is

$$
\left(D_{1}^{-1} N\right)^{\prime} D_{1}\left(D_{1}^{-1} N\right)=N^{\prime} D_{1}^{-1} N
$$

Since we use the chi-square distance associated with the quadratic form of matrix $D_{2}^{-1}$, we have to pre-multiply $N^{\prime} D_{1}^{-1} N$ by $D_{2}^{-1}$ to get the matrix which has as $i$ ts eigenvectors $u$ the linear combinations providing the principal components, $D_{2}^{-1} N^{\prime} D_{1}^{-1}$. The values of the principal components or coordinates along the principal axis are thus given by $\underline{a}=D_{1}^{-1} N \underline{u}$. Since

$$
D_{2}^{-1} N^{\prime} D_{1}^{-1} N \underline{\underline{u}}=\lambda \underline{u}
$$

we have $D_{1}^{-1} \mathrm{~N} \mathrm{D}_{2}^{-1} \mathrm{~N}^{\prime} \underline{\mathrm{a}}=\lambda \underline{\mathrm{a}}$

The other P.C.A. comes down to exchange the principal coordinates with the principal components loadings.

Since the vectors of coordinates are principal components they are in a natural way normalized by:

$$
\sum_{i} \frac{n_{i}}{n} \cdot\left(a_{i}\right)^{2}=\sum_{j} \frac{n_{j}}{n}\left(b_{j}\right)^{2}=\lambda
$$

and the various eigenvectors of $D_{2}^{-1} N^{\prime} D_{1}^{-1} N$ are orthogonal: the scores of various order are uncorrelated variables.

The quantity $\frac{n_{i} .}{n}\left(a_{i}\right)^{2} / \lambda$ is called the "contribution of the $i^{\text {th }}$ category to the eigenvalue".

The reader will have noticed that the two P.C.A. are performed without setting to zero the means of the variables: once the trivial solution $a_{i}=b_{j}=1, \forall i, j$, is discarded, the other solutions are necessarily of zero-mean.

The simultaneous representation of rows and columns of $N$ is therefore nothing else than the superposition of the two separate scatter-plots provided by the two P.C.A. 
The closeness of two row-points or of two column-points is easy to understand: they have roughly the same conditional distributions to the degree that the reduction of dimensionality is not misleading. However, it seems more difficult to interpret the proximity between a row-point and a column-point. He will see further in Section 3 that this proximity can be interpreted in terms of proximity of means of categories.

\subsection{Canonical Decomposition of Contingency Tables}

The whole set of eigenvectors $\underline{a}^{(k)}$ and $\underline{b}^{(k)}$ can give an exact reconstruction of the table:

$$
n_{i j}=\frac{n_{i \cdot n} \cdot j}{n} \quad\left(1+\sum_{k=2} \frac{\min m_{1} m_{2}}{a_{i}^{(k)} b_{j}^{(k)}}\right)
$$

(see Kendall and Stuart, 1961, for instance).

If we use only the first $k$ eigenvecters (including the trivial solution) we obtain the best approximation of the array $\mathrm{N}$ by a matrix of rank $k$ in the following sense:

$$
\text { if } \left.\Phi_{i j}=\frac{n_{i} \cdot n_{j} .}{n} \sum_{l=1}^{k} \frac{a_{i}(1)_{b}(1)}{\lambda_{1}}\right)
$$

then the $\Phi_{i j}$ are such that they minimize:

$$
\sum_{i j} \frac{\left(n_{i j}-\Phi_{i j}\right)^{2}}{n_{i \cdot n \cdot j}}
$$

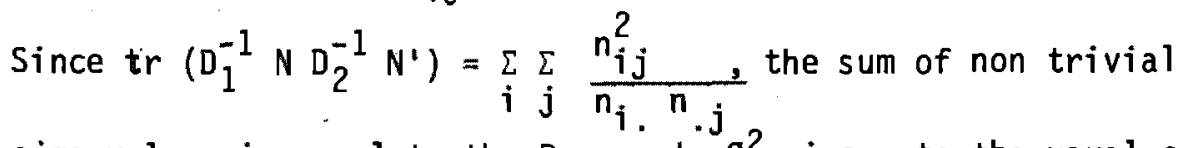
eigenvalues is equal to the Pearson's $\theta^{2}$, i.e., to the usual chisquare statistic for testing the independence divided by

$$
n\left(\sum_{k=2} \lambda_{k}\right)=x^{2}
$$

The preceding properties show that correspondence analysis is a way of analyzing the structure of dependencies in a contingency table. The scores $\underline{a}^{(k)}$ and $\underline{b}^{(k)}$ are pairs of artificial variables each pair representing in some sense a part of the association between $x_{1}$ and $x_{2}$. It may be proved too that the eigenvalue $\lambda_{k}$ is the squared correlation coefficient between the artificial variables $\underline{a}^{(k)}$ and $\underline{b}^{(k)}$ (Hirschfeld, 1935).

\begin{tabular}{|c|c|c|}
\hline eigenvalue & percent & $\begin{array}{l}\text { cumulated } \\
\text { percent }\end{array}$ \\
\hline $\begin{array}{l}.407 \\
.247 \\
.148 \\
.113 \\
.067 \\
.033 \\
.023 \\
.007\end{array}$ & $\begin{array}{l}.389 \\
.236 \\
.142 \\
.108 \\
.065 \\
.031 \\
.022 \\
.007\end{array}$ & $\begin{array}{r}.389 \\
.626 \\
.768 \\
.875 \\
.940 \\
.971 \\
.993 \\
1.000\end{array}$ \\
\hline
\end{tabular}

\subsection{Example}

A correspondence analysis applied to the data of Table 1 gives the following results:

Table 2: Results of correspondence analys is

Thus the first four dimensions "extract" near 90 percent of the structure.

The decomposition of the first four eigenvalues according to rows and columns (formula (8)) is useful for interpretative purposes (Table 3).

Contributions of colums (with the sign of the coordinate)

$\begin{array}{lllll}\text { CERE } & .278+ & .000- & .068- & .460- \\ \text { AGRG } & .222+ & .090+ & .063+ & .330+ \\ \text { VINE } & .001- & .116- & .318+ & .014- \\ \text { FRUI } & .001- & .060- & .142+ & .010- \\ \text { MILK } & .330- & .331+ & .034+ & .075- \\ \text { MEAT } & .056- & .123+ & .295- & .061+ \\ \text { MIX } & .048- & .005- & .060- & .023+ \\ \text { SHEEP } & .039- & .270- & .020+ & .002+ \\ \text { AGSH } & .025+ & .004+ & .000- & .024+\end{array}$




$\begin{array}{lllll}\text { ILDF } & .097 & .004 & .009 & .109 \\ \text { CHAM } & .083 & .019 & .006 & .026 \\ \text { PICA } & .108 & .054 & .027 & .203 \\ \text { HNOR } & .008 & .010 & .000 & .044 \\ \text { CENT } & .200 & .000 & .043 & .281 \\ \text { BNOR } & .087 & .102 & .001 & .009 \\ \text { BOUR } & .002 & .044 & .133 & .005 \\ \text { NORD } & .030 & .034 & .021 & .166 \\ \text { LORR } & .001 & .009 & .004 & .000 \\ \text { ALSA } & .003 & .000 & .004 & .001 \\ \text { FRCO } & .041 & .048 & .004 & .019 \\ \text { LOIR } & .068 & .001 & .052 & .013 \\ \text { BRET } & .013 & .183 & .020 & .033 \\ \text { POIT } & .001 & .029 & .005 & .002 \\ \text { AQUI } & .002 & .026 & .077 & .005 \\ \text { MIDI } & .000 & .030 & .001 & .002 \\ \text { LIMO } & .043 & .133 & .131 & .062 \\ \text { RHON } & .028 & .001 & .040 & .007 \\ \text { AUVE } & .082 & .000 & .019 & .000 \\ \text { LANG } & .009 & .152 & .240 & .006 \\ \text { PROV } & .000 & .093 & .164 & .004 \\ \text { CORS } & .003 & .031 & .000 & .002\end{array}$

Table 3: Decomposition of eigenvalues according to rows and columns

We see clearly on the diagram (Fig. 1) that the horizontal axis separates the regions into two main categories: those specializing in milk production at the left side (Bretagne, Basse-Normandie.) and those specializing in cereals and general agriculture on the right side (Ile de France, Centre, Picardie mainly). This represents the main feature of the data set.

The second dimension is characterized by milk production again, opposed this time by "sheep", "wines" and "fruit". We find at the bottom of the map regions of the Mediterranean coast.

The third axis is characteristic of an opposition between regions devoted mainly to "wine production" and regions devoted to "meat production". The fourth dimension provides no new information but allows the separation between "cereals" and "general agriculture" which was not distinguishable along the first axis.

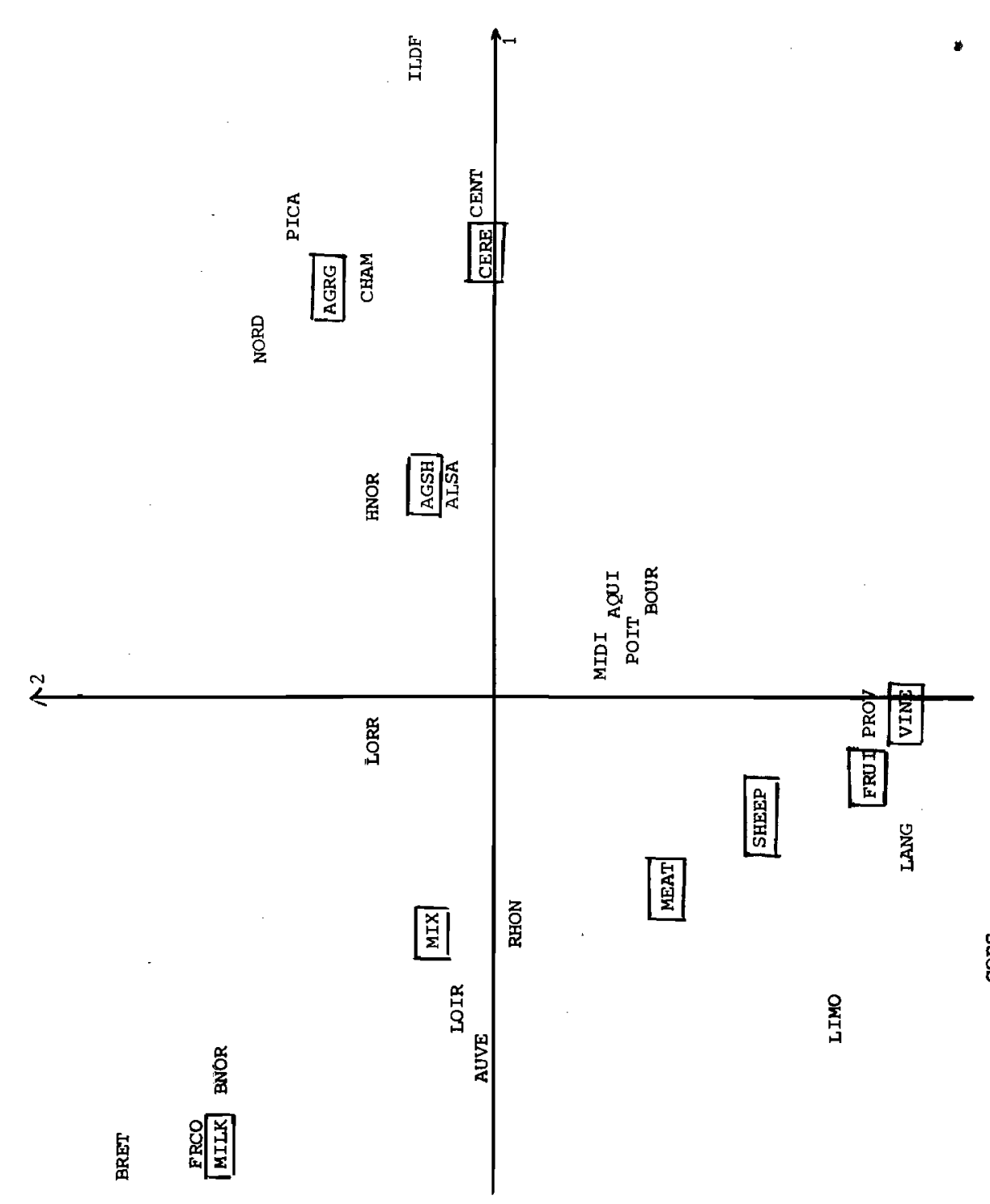

Figure 1: Joint representation of regions and agricultural land users. 
nce the chi-square distance is an Euclidean distance, it is posole to use metric methods of cluster analysis in order to classify didentify common spatial patterns. For clustering regions, 's hierarchical technique seems appropriate because for continacy tables it comes down to the following algorithm: at each step merge the two lines of the contingency table that lead to the nimal loss of the phi-square measure of association. The hierarical level of a cluster is exactly equal to that loss and the ns of all levels is thus, of course, equal to the $\emptyset^{2}$ statistic the whole array (Benzecri, 1973; Jambu, 1978; Bouroche and porta, 1980).

reader should note that Ward's method consists of maximizing each step the intercluster dispersion measured as the weighted an of the squared distances between centroids, or equivalently minimizing the within-cluster dispersion.

result is the following tree diagram (Figure 2 ).

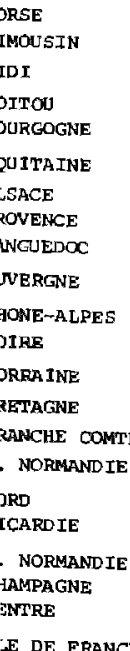

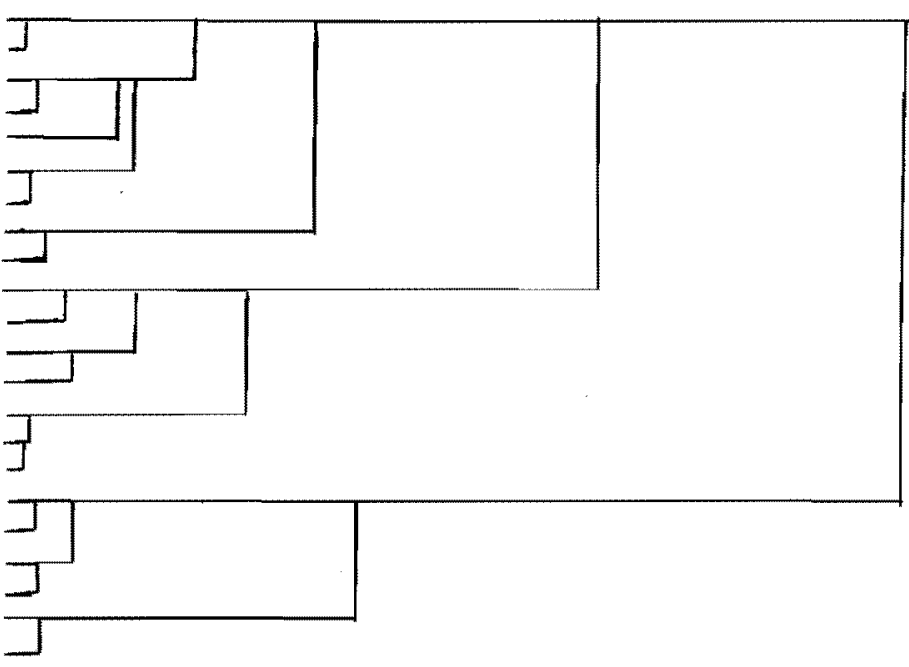

We may identify distinctly 5 clusters followed by their main characteristics:

1. Centre, Ile de France/ cereals

2. Nord, Picardie, Haute-Normandie, Champagne/ general agriculture

3. Basse-Normandie, France-Comté, Bretagne, Lorraine, Loire, Rhône-

Alpes, Auvergne/ milk production

4. Provence, Languedoc/ fruits, wines

5. Alsace, Aquitaine, Bourgogne, Poitou, Midi, Limousin, Corse/breeding

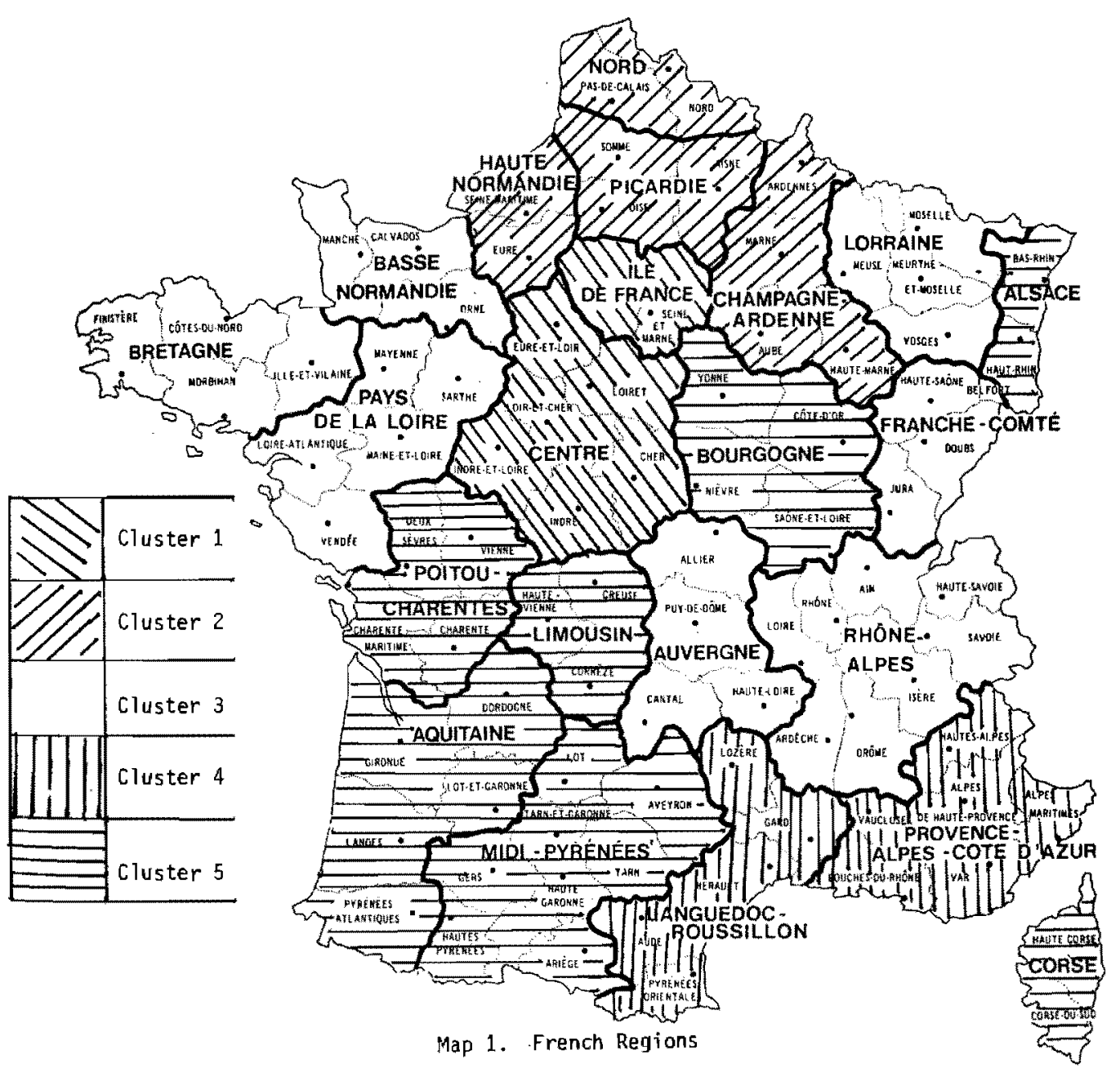



equation (15) looks like a correspondence analys is equation (cf. equation (5)). Indeed, $\mathrm{pI}$ is the diagonal matrix of row totals of $X, D$ is the diagonal matrix of column totals of $X$ and

$1 \times D^{-1} X^{\prime}$ is the product of the two "conditional" arrays associated with $X$. Thus it is necessary simply to apply correspondence analys is to $X$, formally considered as a contingency table.

Using the duality between solutions associated with rows and columns it follows that:

$$
\underline{z}=\lambda^{-1 / 2} \frac{1}{p} X \underline{a}=\lambda^{-1 / 2}\left(\frac{1}{p} \sum X_{j} \underline{a}_{j}\right)
$$

where vector $\underline{a}$ (made of subvectors $\underline{a}_{j}$ ) is a solution of:

$$
\frac{1}{p} D^{-1} X^{\prime} X \underline{a}=\lambda \underline{a}
$$

which is a more convenient equation than (15) since it is of size $\sum m_{j}$ and not of size $n$.

Applying again the duality relations gives:

$$
\underline{a}=\lambda^{-1 / 2} D^{-1} X^{\prime} \underline{z}
$$

Apart from the constant $\lambda^{-1 / 2}$ the coordinate of a column of $X$ along an axis of correspondence analysis is just the mean value of variable $z$ for those individuals belonging to the category corresponding to this column.

Equation (17) establishes conversely an analogous property for the rows: we find again here the principle of dual scaling used in section 2 which could have been taken as a definition of multiple correspondence analys is.

It must be pointed out that here the sum of non-trivial eigenvalues (there exist $\Sigma m_{j}-p$ such eigenvalues) is a constant equal to $\left(\frac{1}{\bar{p}} \Sigma m_{j}\right)-1$ and has no statistical meaning. One should not attach much importance to the percentages of explained variance which are generally small since $\lambda<1$.

If $p=2$ multiple correspondence analysis gives the same results as usual correspondence analysis: precisely the super vector a contains as subvectors the two-vectors $\underline{a}$ and $\underline{b}$ of coordinates of rows and and columns of the contingency table $\mathrm{N}=X_{1}^{\prime} X_{2}$. The eigenvalues, however, are not the same: they are transformed by

$\frac{1 \pm \sqrt{\lambda}}{2}$

If in the data set some variables are numerical, it is possible to handle them after splitting their values into categories.

Surprisingly enough, the discretization of numerical variables is very efficient and does not lead to a loss of information: actually, it is a way to avoid the linearity of classical treatments (Masson, 1974; Gifi, 1981).

\subsection{An Example}

From a study concerning the standard of living in Europe ("L'Expansion" April, 1979) we have taken the following array giving the household expenditure according to eight variables, each with three categories $(1=$ low, 2 = medium, 3 = high). (see Table 4$)$.

Since there are 8 variables, each with three categories, there are 24-8 = 16 non trivial eigenvalues the sum of which equals 2 .

The first four eigenvalues are:

$$
\lambda_{1}=0.380 \quad \lambda_{2}=0.349 \quad \lambda_{3}=0.219 \quad \lambda_{4}=0.184
$$

The first principal plane (Figure 4) reveals the following features: the horizontal axis shows a strong difference between countries where household expenditures for food are high (Greece, Portugal, Spain,

Italy, Ireland) and those where household expenditures for home are

high (Belgium, West Germany, France, Finland). The first principal component is positively correlated with variable HOME and negatively with variable FOOD as it can be seen with the order of categories along the first axis.

The vertical axis isolates a group of three countries (Switzerland, Sweden, Denmark) characterized by a high level of housing and heating expenditure and $\mathrm{a}^{-}$low level of clothing expenditures.

A cluster analysis using Ward's algorithm gives a confirmation of the three clusters outlined in Figure 4 .

Here cluster analysis, applied to the rows of the disjunctive array with the chi-square metric, presents some interesting features. The similarity measure associated with the chi-square metric is a (weighted) scalar product between rows: 


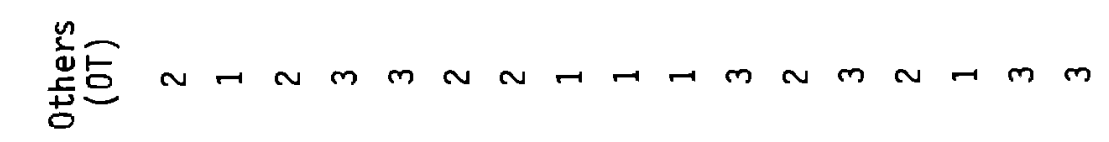

ᄃ

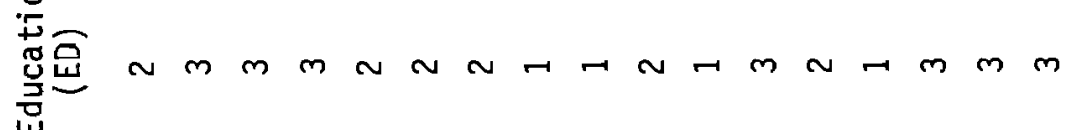

$+$

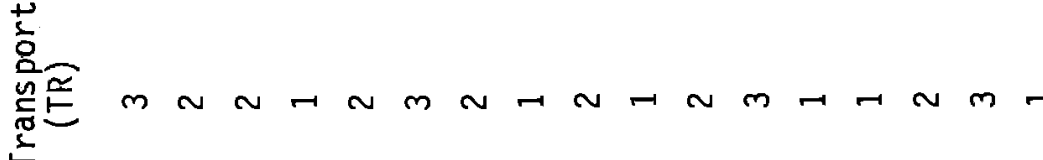

产岸 $\sim \sim m-n \sim m \sim-n \rightarrow m-n \rightarrow m$

产

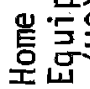

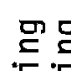

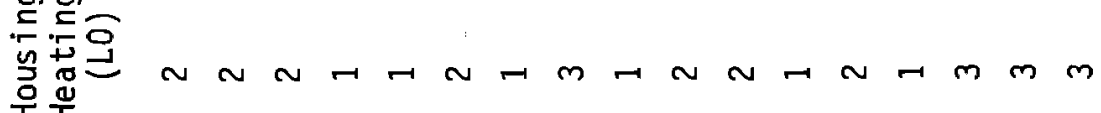

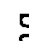

至崖 뭉운

$-T-\sim m \sim-m m m-r \rightarrow m \sim-N$

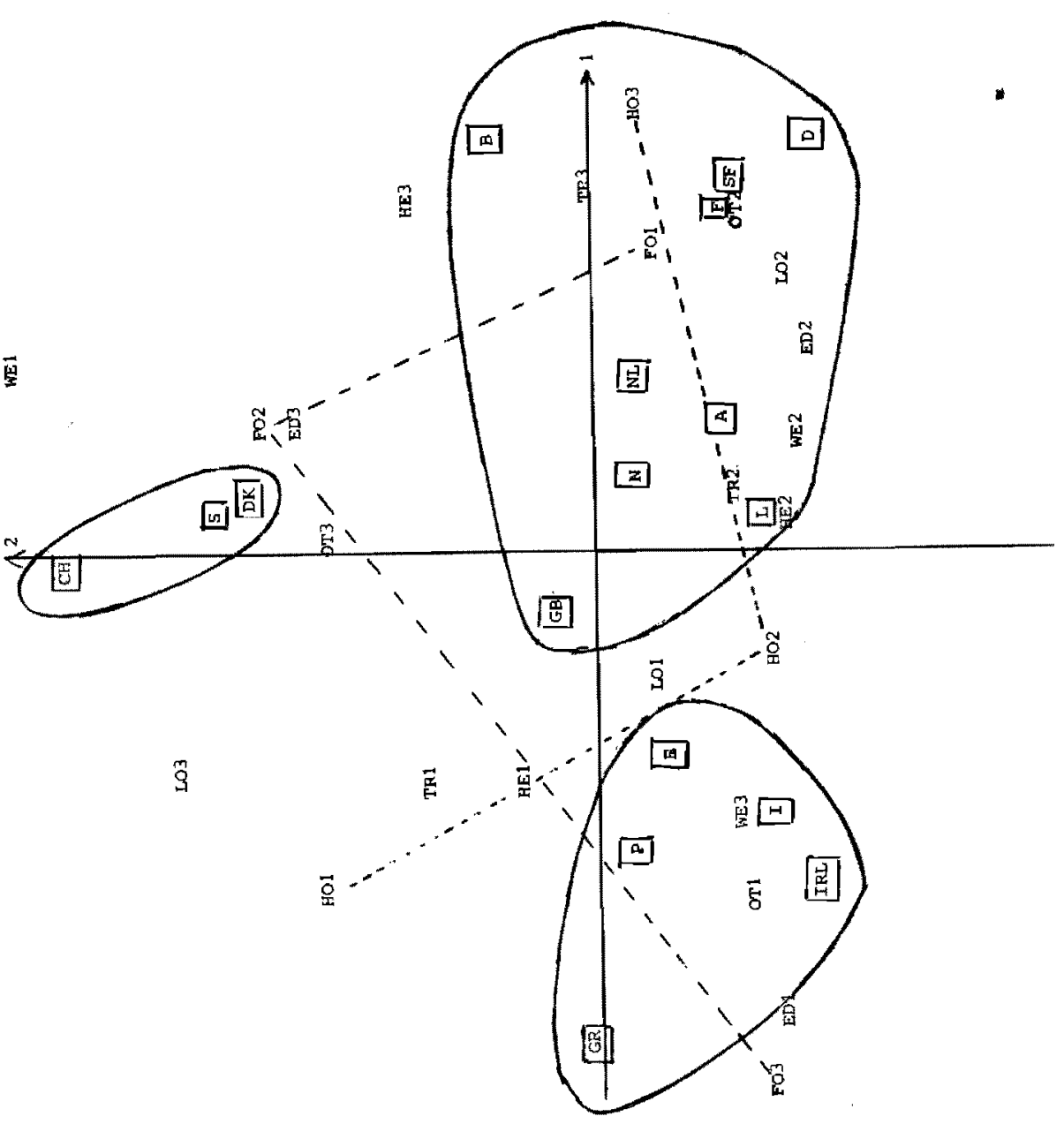

Figure 3. Results of a qualitative corresoondence analysis

$$
S\left(i, i^{\prime}\right)=\sum_{j} \frac{n p}{n_{\cdot j}} x_{i}^{j} x_{i \prime}^{j}
$$

Since the elements $x_{j}^{j}$ are 0 or $1, S\left(i, i^{\prime}\right)$ is the sum over the $p$ categorical variables of the following elementary similarity measure:

$S_{x}\left(i, i^{\prime}\right)=0$ if $i$ and $i^{\prime}$ do not belong to the same category of $x$ $=\frac{n p}{n_{\cdot j}}$ if $i$ and $i$ ' belong to the category $j$ of $x$. 


\section{REFERENCES}

Benzécri, J.P., 1973, L'analyse des données vol. 1 Taxonomie (Dunod, Paris).

Benzécri, J.P., 1973, L'analyse des données vol II Correspondances (Dunod, Paris).

Bouroche, J.M. and G. Saporta, 1980, L'analyse des données, Collection Que sais-je no. 1854 (Presses Universitaires de France, Paris).

Deville, J.C. and G. Saporta, 1983, Correspondence analys is with an extension towards nominal time series, Journal of Econometrics $22,152-164$.

De Leeuw, J. and J. van Rijckevorse1, 1979, Homals and Princals, in E. Diday (ed.), Data analysis and Informatics (North-Holland, Ams terdam) 231-242.

Gifi, A., 1981, Non-linear Multivariate Analys is (Department of Data Theory, Leyden University, Leyden).

Gnanadesikan, R., 1977, Methods for Statistical Data Analysis of Multivariate Observations (John Wiley, New Yrok).

Guttman, L., 1941, The quantification of a class of attributes: a theory and method of scale construction, in: P. Horst (ed.), The prediction of personal adjustment (Social Science Research Council, New York) 319-348.

Hayashi, C., 1950, On the quantification of qualitative data from the mathematico-statistical point of view, Annals of the Institute of Mathematical Statistics 2, 35-47.

Hill, M.0., 1974, Correspondence analysis: a neglected multivariate method, Applied Statistics 23, 340-354.

Hirschfeld, H.0., 1935, A connection between correlation and contingency. Proceedings of the Cambridge Philosophical Society $31,520-524$.

Jambu, M., 1978, Classification automatique pour 1 'analyse des donées (Dunod, Paris).

Kendall, M.G., and A. Stuart, 1961, The advanced theory of statistics Vol. 2: Inference and relationship (Griffin, London).

Lebart, L., A. Morineau, and N. Tabard, 1977, Techniques de 1a description statistique (Dunod, Paris).
Mackeon, J.J., 1966, Canonical analysis: some relations between canonical correlation, factor analysis, discriminant functions analysis and scaling theory. Psychometric monograph no. 13 (The Psychometric Society, New York).

Masson, M., 1974, Processus lineaires et analyse de données non linéaire, Thèse (Universitê Pierre et Marie Curie, Paris).

Tukey, J., 1977, Exploratory data analysis (Addison Wesley, Reading). 